temporary nature and easily overcome in a few years. On the subject of procreation and marriage, heredity and race, the same pessimistic and fatalistic crudity is displayed. Almost every physical, mental, psychic quality of man seems to be inherited and unalterable, practically none produced or aggravated by economic, environmental or other conditions of life. No notice is taken of the fact that not a few manifestations of neurotic persons mentioned in the list of indications for the most cruel interferences with their lives are not hereditary and are curable, or at least improvable to such an extent as to make the disability from which they are suffering negligible to the community.
The chapters dealing with eugenics, racial hygiene and measures tending to the "gradual purification and improvement of the hereditary stream of our people" abandon in many respects the scientific basis of causation and replace it by the nebulous mysticism of the Nazi creed and empty catchwords. The profession of medicine, which is justly proud of, and continually aims at, scientific fundamentals and independent objectivity, is thus degraded to a state of servitude to the views of the prevailing political party, in which the medical officer of health is the expert party representative.

The addenda are in conformity with the general trend of the book.

X. Y. Z.

\title{
Agricultural Chemistry
}

A Practical Course in Agricultural Chemistry: for Senior Students of Agriculture, Dairying, Horticulture and Poultry Husbandry. By Frank Knowles and Dr. J. Elphin Watkin. Pp. ix +188 . (London: Macmillan and Co., Ltd., 1937.) 10s. net.

GORMERLY agricultural chemistry was one of $F$ three main subjects in courses on agriculture, but to-day increasing specialization inside the industry itself has been accompanied by a multiplication in the courses available in the university departments and colleges engaged in agricultural education. A student may present himself for a course in horticulture, or dairying, or poultrykeeping, or in agriculture ; he may be an intending producer, technician, adviser, teacher, or specialist ; but in any event a goodly proportion of his time will be spent on agricultural chemistry. For most students, the materials and vital processes concerned are the same, but the emphasis on them varies according to the type of specialization desired or the nature of the qualification sought.

The authors have had this diverse field in mind, in their effort to provide what has hitherto been lacking, a laboratory text-book which would adequately serve all types of senior student. So far as methods of estimation are concerned the result is to be commended, but while laboratory estimations are a valuable help to a student, they are less effective if unaccompanied by, or based on, qualitative work, an aspect which seems to have been lost sight of in some chapters. On this account, and because of the impracticability of elaborate technique in ordinary classes, the book may prove less helpful to beginners than to advanced students.

In the field, soil is studied as a natural object, but in the laboratory it becomes and is treated as a dead material. Before it is 'prepared' for analysis, however, much ean be learned by close examination, by hand and eye. The main constituents of soil are worth similar attention, but the chapter on soils neglects this aspect of the subject. The order of presentation of the determinations seems to lack purpose, such as is obvious where mechanical analysis leads up to physical properties, and chemical analysis is followed by base status and availability of nutrients.

In the chapter on fertilizers, a few exercises are introduced to illustrate manufacturing processes; but the need of the student to grasp their simple physical and chemical properties is ignored. It is to be regretted that farmyard manure is considered mainly on an N.P.K. basis.

By contrast, the chapter on biochemistry is based on qualitative work, and the whole field of materials-except flesh-is explored by informative exercises in isolating the chief constituents. The methods of analysis for feeding stuffs include some associated with special features of individual commodities, but this section is not set out in such a way as to strengthen the student's knowledge of feeding stuffs as a whole, as distinct from his ability to analyse them. The excellent chapter on dairy products includes material which has not hitherto appeared in a student's text-book.

The section on water analysis contains methods of estimation alone, but that on insecticides and fungicides, an innovation in this class of book, contains in addition informative exercises on their composition and important properties.

The book as a whole is compact, comprehensive, and clearly written, and should be found of use to all classes of agricultural students. H. H. N. 